\title{
CORRECTION
}

\section{Correction to: Polyphenols, methylxanthines, fatty acids and minerals in cocoa beans and cocoa products}

\author{
Melania Grassia ${ }^{1} \cdot$ Giancarlo Salvatori $^{2} \cdot$ Maria Roberti $^{3} \cdot$ Diego Planeta $^{4} \cdot$ Luciano Cinquanta $^{4}$
}

Published online: 3 August 2019

(c) Springer Science+Business Media, LLC, part of Springer Nature 2019

\section{Correction to: Journal of Food Measurement and Characterization https://doi.org/10.1007/s11694-019-00089-5}

The original version of the article unfortunately contained error in author group. First and family name of all authors were swapped and below is the corrected information.

Melania Grassia-First name - Melania; Family name - Grassia

Giancarlo Salvatori-First name - Giancarlo; Family name - Salvatori

Maria Roberti-First name - Maria; Family name - Roberti

Diego Planeta-First name - Diego; Family name - Planeta
Luciano Cinquanta_-First name - Luciano; Family name - Cinquanta

This has been corrected with this erratum.

Publisher's Note Springer Nature remains neutral with regard to jurisdictional claims in published maps and institutional affiliations.

The original article can be found online at https://doi.org/10.1007/ s11694-019-00089-5.

Luciano Cinquanta

luciano.cinquanta@unipa.it

1 Dipartimento di Agricoltura, Ambiente e Alimenti,

Università del Molise, Campobasso, Italy

2 Dipartimento di Medicina e Scienze della

Salute'’V. Tiberio', Università del Molise, Campobasso, Italy

3 ARPAm Molise, Campobasso, Italy

4 Dipartimento Scienze Agrarie, Alimentari e Forestali, Università di Palermo, Viale delle Scienze, 90128 Palermo, Italy 